\title{
Cryptic genetic structure in an Argentinian population of Anastrepha fraterculus (Diptera: Tephritidae) evidenced by SSR markers and quantitative traits
}

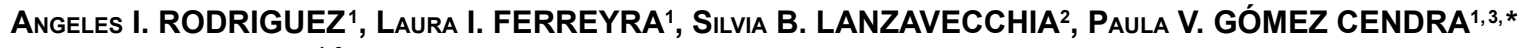 \\ and JUAN C. VILARDI ${ }^{1,3, * *}$ \\ ${ }^{1}$ Genética de Poblaciones Aplicada (GPA), Facultad de Ciencias Exactas y Naturales, Departamento de Ecología, Genética \\ y Evolución, Universidad de Buenos Aires, Intendente Güiraldes 2160, C.P. 1428, Buenos Aires, Argentina; \\ e-mails: irielrod@gmail.com, Iferreyra@ege.fcen.uba.ar, paugomez@ege.fcen.uba.ar, vilardi10@gmail.com \\ ${ }^{2}$ Instituto de Genética "Ewald A. Favret", Instituto Nacional de Tecnología Agropecuaria, Hurlingham, Argentina; \\ e-mail: lanzavecchia.silvia@inta.gob.ar
}

${ }^{3}$ CONICET-Universidad de Buenos Aires, Instituto de Ecología, Genética y Evolución (IEGEBA), Buenos Aires, Argentina

Key words. Diptera, Tephritidae, fruit flies, Anastrepha fraterculus, SSR markers, genetic structure, hierarchical analyses, morphometry, multivariate analysis, oviposition strategy

\begin{abstract}
In some regions of Argentina and Brazil, the South American fruit fly Anastrepha fraterculus (Wied.) (Diptera: Tephritidae) causes significant damage to crops. An efficient integrated management program requires knowledge of pest population dynamics, dispersion patterns, sexual and oviposition behaviour, and adaptive landscape. The present study combined simple sequence repeat (SSR) molecular markers and morphometric datasets in order to analyse the population structure and infer the oviposition resource use strategy of the females. Infested guava fruits were collected from nine wild trees in Tucumán, Argentina, and a total of 140 adult $A$. fraterculus were recovered. These were then measured for six morphometric traits and 89 of them were genotyped for eight SSR loci. Genetic variability estimates were high (expected heterozygosity $=0.71$, allelic richness $=12.5$ ), with 8 to 20 alleles per locus. According to Wright's F-statistics estimates, the highest proportion (83\%) of genetic variation occurred within individuals while variance between and within fruits were similar $(\approx 8.5 \%)$. Analysis of the cryptic genetic structure based on SSR using different approaches, namely discriminant analysis of principal components (DAPC) and sparse non-negative matrix factorization (SNMF), yielded results consistent with the occurrence of two clusters with virtually no admixture. Average kinship between individuals which had emerged from the same fruit $(0.07)$ was lower than that expected for full-sib families. Univariate and multivariate analyses of phenotypic data showed $54-66 \%$ of variance among individuals within fruits and $34-46 \%$ among fruits. The comparison between phenotypic $\left(P_{S T}\right)$ and molecular $\left(F_{S T}\right)$ differentiation identified wing width and length as possible target of positive selection. The average kinship and high genetic variation within fruits, together with the highly significant genetic differentiation among fruits, supports the hypothesis that each fruit was colonised by about three ovipositing females. The results also indicate that females were able to disperse widely from the emergence site before mating and starting oviposition activity.
\end{abstract}

\section{INTRODUCTION}

The South American fruit fly, Anastrepha fraterculus (Wiedemann), belongs to the superfamily Tephritoidae; this includes major world pests that use wild and commercial species of fruit as their feeding and breeding sites (Aluja, 1994; Uchôa-Fernandes et al., 2003). Anastrepha fraterculus is a complex of cryptic species with the potential to infest several hosts. The nominal species range is very wide, from the south of the United States (Texas) to central Argentina (Dos Santos et al., 2001; Vera et al.,
2006). Along this distribution, important morphological, genetic, and behavioural differences have been recorded, supporting the occurrence of at least eight different biological entities (Hernández-Ortiz et al., 2015) considered synmorphic species (Hernández-Ortiz et al., 2004; Cladera et al., 2014; Hendrichs et al., 2015; Vaníčková et al., 2015). In particular, the variation within the complex refers to specific host exploitation (Rocha \& Selivon, 2004; Alberti et al., 2008), morphology (Stone, 1942), karyotype and isoenzymes (Morgante et al., 1980; Steck, 1991; Seliv-

\footnotetext{
* Corresponding author; e-mail: paugomez@ege.fcen.uba.ar

** A.I. Rodriguez and L.I. Ferreyra should be considered joint first authors. P.V. Gómez Cendra and J.C. Vilardi should be considered joint senior authors.
} 
on et al., 2005), egg morphology (Stone, 1942; Selivon \& Perondini, 1998), hybridization (Norrbom \& Foote, 1989), mitochondrial DNA (Carballo et al., 2001; Smith-Caldas et al., 2001), ribosomal DNA (Sutton et al., 2015), highly repetitive DNA (Bueno, 2000), morphometric characters (Hernández-Ortiz et al., 2004, 2012, 2015; Selivon et al., 2004; Canal et al., 2015), mating compatibility (Vera et al., 2006), reproductive isolation (Selivon et al., 1999), and behaviour (Vera et al., 2006; Cáceres et al., 2009; Devescovi et al., 2014; Dias et al., 2016; Roriz et al., 2017).

In Argentina, $A$. fraterculus has been reported as a fruit fly species of economic and quarantine importance in large fruit production areas (IAEA, 1999). Information from multiple sources (reviewed by Cladera et al., 2014), including isozymes and mitochondrial DNA (Alberti et al., 2002, 2008) and sexual compatibility assays (Petit-Marty et al., 2004a, b) supports the occurrence of a single morphotype named "Brazilian-1" by Hernández-Ortiz et al. (2012, 2015) (also referred as A. sp.1 aff. fraterculus by Yamada \& Selivon, 2001). This morphotype is present in Argentina in the sub-tropical Northeast and Northwest regions, where the weather is warm and humid (Alberti et al., 2002; Ovruski et al., 2003). Between these regions, the semi-arid bio-geographic province of Chaco represents a natural barrier (Alberti et al., 2002; Gómez Cendra et al., 2014).

In spite of the fact that only one morphotype has been recognised for Argentina, recent results by Oroño et al. (2013) suggested that differences in chemical composition among host fruits may result in a complex internal structure of wild populations. In particular, ISSR marker analysis showed significant genetic differentiation between populations exploiting different synchronic species.

Research on the genetic variability distribution in wild populations, colonization patterns, phylogeography, and gene flow is important for pest control programs. Briefly, the size of management areas and the establishment of phytosanitary barriers should be determined based on population structure, adaptive landscape, dispersal ability, and mating and oviposition behaviour. These information sources would contribute to increasing the efficiency of integrated pest management, and an eventual implementation of the sterile insect technique (SIT) against $A$. fraterculus in Argentina (Klassen \& Curtis, 2005).

The suitable habitat structure for fruit flies fluctuates between early (egg to third-instar larva) and adult stages, from a patchy (coarse-grained) to a continuous (finegrained) distribution. Adult population structure is mainly affected by fly dispersal during the period from emergence to sexual maturity, mating, and oviposition. During this stage, the population is assumed to be large and to mate at random. A finite number of inseminated females colonise available host fruits, meaning that the distribution of genetic variation of larvae within and among fruits depends largely on the effective number of ovipositing females per fruit. The available information indicates that one copulation is enough for the fertilization of all eggs of a single female, and the refractory period is so long (16 days in laboratory conditions to 19 days in the wild) that, in nature, A. fraterculus might be considered functionally monogamous (Abraham et al., 2011). Its oviposition behaviour was first observed by Barros et al. (1983) who identified three stages: searching, puncturing (egg-laying), and dragging of the ovipositor over the fruit surface. Prokopy et al. (1982) evaluated the relation between the ovipositor dragging and the oviposition of a second female on the same fruit, proposing that this behaviour is a way to disperse an "oviposition-deterring pheromone". According to their observations, it is expected that each fruit is colonised by one or a few fertilised females.

With the general purpose of producing information on the biology of $A$. fraterculus, the objective of our work was to evaluate the fine-scale population genetic structure and oviposition resource use of a natural population of this species in a guava orchard in northern Argentina, where no pest management had been conducted whatsoever.

Following Prokopy et al. (1982), our working hypothesis was that individuals emerging from the same fruit originated from a small number of ovipositing females. Consequently they should be more related and have a more similar multilocus genotype and multivariate phenotype than those which develop in different host fruits. To test this hypothesis, we applied a hierarchical sampling of an $A$. fraterculus wild population and evaluated the distribution of genetic and morphometric variance components at two levels (fruit and tree), based on eight microsatellite markers and six quantitative traits. The occurrence of cryptic structure was also evaluated from these molecular markers and phenotypic traits by estimating admixture coefficients with different approaches.

\section{MATERIALS AND METHODS}

\section{Sampling of Anastrepha fraterculus}

The analysed A. fraterculus population is located near Horco Molle, Tucumán, Argentina. Geographically, it covers an area of 100 ha, ranging from $26^{\circ} 47^{\prime} 22.93^{\prime \prime} \mathrm{S}$ to $26^{\circ} 46^{\prime} 21.67^{\prime \prime} \mathrm{S}$ and from $65^{\circ} 20^{\prime} 27^{\prime \prime} \mathrm{W}$ to $65^{\circ} 19^{\prime} 32.19^{\prime \prime} \mathrm{W}$. It is an orchard without any cultural pest control which might affect fly population properties or individual survival.

The sampling was conducted in 2010, from February to April during the fruiting season. Approximately 30-40 guava (Psidium guajava L.) fruits with evidence of infestation by tephritid flies (oviposition holes) were collected from each of 10 trees (making a total of 350). Although all fruits were sent for processing at the laboratory in Buenos Aires, about 200 needed to be discarded because they arrived in an advanced state of rotting. The remaining guava fruits were placed in individual containers on sandy litter, covered with a piece of gauze, and kept at $20-25^{\circ} \mathrm{C}$. Each container was checked on a daily basis for emerged thirdinstar larvae and pupae until the fruits started to dry, discarding those that failed to yield adult flies. All pupae from each fruit were transferred to a flask with a sandy substrate, which was kept at room temperature and daily checked for adult emergence. Emerged adults were labelled according to the fruit and tree from which they emerged and stored in Eppendorf tubes at $-20^{\circ} \mathrm{C}$. Based on the evidence mentioned in the previous section, all A. fraterculus recovered individuals were considered to be the "Brazilian-1" morphotype. A few emerged Ceratitis capitata flies were discarded. 
To evaluate the distribution of genetic and morphological variance, a hierarchical design was applied considering the levels tree and fruit (nested in tree). In order to allow the assessment of within fruit differentiation, fruits that yielded less than 4 emerged adults (about one third of those effectively producing adults) were discarded. As females were missing in many fruits, all morphometric measurements were made only on males emerging from three fruits per tree, to prevent problems associated with sexual dimorphism and sampling unbalance. As a consequence of this limitation, the final number of fruits retained for the analysis was 27. This number represented the best trade-off between sampling size and similar numbers of fruits per tree.

\section{DNA extraction and genotyping procedure}

A total of 89 of the 140 adult individuals recovered were genotyped, representing 18 fruits (two fruits per tree, with 4-6 individuals each).

DNA extraction followed the protocol specified by Baruffi et al. (1995) with modifications (Lanzavecchia et al., 2014). Eight SSR markers were analysed using the primers A115, D105, A120, A7, C103, A10, A112, and A122 developed by Lanzavecchia et al. (2014). DNA was amplified using the following PCR conditions: one cycle at $95^{\circ} \mathrm{C}(2 \mathrm{~min}), 30$ cycles at $95^{\circ} \mathrm{C}(30 \mathrm{~s}), 58^{\circ} \mathrm{C}$ $(30 \mathrm{~s})$ and $72^{\circ} \mathrm{C}(30 \mathrm{~s})$, and final elongation at $72^{\circ} \mathrm{C}(10 \mathrm{~min})$. Amplification was performed per Lanzavecchia et al. (2014) in a Veriti Thermal Cycler, Applied Biosystems, using a final volume of $30 \mu \mathrm{l}$ for the reaction mix.

PCR products were run in an automatic sequencer 3500xl Genetic Analyser, Applied Biosystems with GS 500 LIZ marker and processed by GeneMarker ${ }^{\circledR}$ v.2.4 (SoftGenetics Llc., www.softgenetics.com).

\section{Microsatellite statistical analysis}

The discriminant power of the analysed loci was evaluated by means of a genotype accumulation curve obtained with the poppr package (Kamvar et al., 2015) of $R$ software v.3.4.3 (R Core Team, 2017). The hypothesis of an independent distribution of the analysed loci was evaluated by means of the index of association $I_{a}$ (Brown et al., 1980) and the standardised index of association $\overline{r_{D}}$ (Agapow \& Burt, 2001). These coefficients and their significance (obtained by a permutation test) were estimated with the same package.

The genetic variability of each locus was quantified by the total number of alleles $(A)$, the observed $\left(H_{O}\right)$, and the unbiased expected heterozygosity $\left(H_{E}\right)$ per fruit, the total expected heterozygosity $\left(H_{T}\right)$ (estimated according to Nei \& Chesser, 1983), and the allelic richness $\left(R_{A}\right)$ (El Mousadik \& Petit, 1996) per locus and fruit, estimated using the hierfstat package (Goudet, 2006) of $R$. The excess/deficiency of heterozygotes in each locus within each fruit was evaluated using the $U$ score (Rousset \& Raymond, 1995) estimated with the package HWxtest of $R$ (Engels, 2016).

The results of the tests for linkage disequilibrium and excess/ deficiency of heterozygotes were corrected for multiple tests analysis, applying the method of Benjamini \& Hochberg (1995).

The genetic structure of the whole sample was analysed by $F$ statistics (Wright, 1951, 1965), as defined by Weir \& Cockerham (1984). The fixation indices $F_{I S}$ and non-hierarchical $F_{S T}$, as well as their confidence interval ( $95 \%$, based on 1,000 replicates), were calculated with the package hierfstat of $R$. The significance of genetic differentiation among fruits (or trees) was obtained with the same package by G-statistics (based on 1,999 permutations).

To assess whether the individuals showed association according to the fruit they were caught from, two approaches were applied. The first one involved a minimum spanning network (MSN) (Bandelt et al., 1999) obtained from a pairwise matrix of genetic distances (Reynolds et al., 1983) with the poppr package. The second approach was based on the estimates of pairwise kinship coefficients calculated according to Loiselle et al. (1995) with the function eco.kin.loiselle of the package EcoGenetics (Roser et al., 2017) of $R$. Then, for both coefficients, distances, and kinships, $t$-tests were used to compare estimates obtained between individuals from the same fruit with estimates for individuals from different fruits.

Oroño et al. (2013) demonstrated significant genetic differences among groups defined a priori on the basis of host species in an A. fraterculus population, sampled in a locality close to that analysed here. In our analysis, we assessed the possible occurrence of cryptic genetic structure that cannot be detected when groups are defined using prior subjective criteria. This issue was evaluated by two methods: (1) discriminant analysis of principal components (DAPC) (Jombart et al., 2010), and (2) admixture coefficients using sparse non-negative matrix factorization (SNMF) algorithms (Frichot et al., 2014). DAPC is a statistical approach designed to identify and describe clusters of individuals without the need for any prior information on individual groups (Jombart et al., 2010). It has some advantages with respect to Bayesian clustering algorithms, such as those implemented for molecular data in structure (Pritchard et al., 2000; Falush et al., 2003) or BAPS (Corander et al., 2000; Tang et al., 2009). DAPC produces similar results, but is much more efficient in terms of processing speed, with the additional advantage that it may be also applied to morphological quantitative data (Jombart et al., 2010). We conducted the analysis with the package adegenet (Jombart, 2008) without prior information on individual groups. Clusters were identified using the method of successive $K$-means implemented in the function find.clusters and used as priors for the DAPC procedure. We covered an interval of possible number of clusters $(K)$ from 1 to 9 . The best $K$ value is usually selected on the basis of the lowest Bayesian information criterion (BIC). An additional criterion, when $B I C$ is similar for different $K$ values, is based on the asymmetry $(A s)$ in individual assignment defined as:

$A s=\sum_{i=1}^{N} \frac{1}{K} \sum_{j=1}^{K}\left(P_{i j}-\frac{1}{k}\right)^{2}$

where $i$ represents the individual, $j$ is the inferred cluster, $P_{i j}$ is the posterior assignment of individual $i$ to cluster $j$. As is at a maximum when the probability of assignment of individuals to each cluster takes values equal to 1 or 0 , and is at a minimum when individual assignment probabilities are similar for all clusters. The significance of genetic differences between the clusters identified by DAPC was evaluated conducting $F$ statistic analysis considering these clusters as grouping factor.

SNMF was carried out with the package LEA (Frichot \& François, 2015) of $R$. As recommended by Frichot et al. (2014), the optimal number of clusters is based on a minimal entropy criterion, which depends on the number of clusters $(K)$ and a regularization parameter $(a)$. Empirically, in a first exploratory run we tested 6 levels for the $a$ value and a $K$ interval from 1 to 4 , by estimating the corresponding entropy using 100,000 iterations and 10 repetitions. The conditions with the lowest entropy were selected as the optimum for the final run, with 10 million iterations and 10 repetitions.

The consistency of individual clusterings, obtained with DAPC and SNMF from molecular data, was evaluated by an independence Chi-square test. 


\section{Morphometric analysis}

Morphometric traits were measured in 140 males, 89 of which were the same individuals genotyped and used for molecular analyses as described above. The sample was composed of 4-10 individuals per fruit, three fruits per tree, from nine trees.

Six traits related to body size, head shape, and flying ability were measured and named as: thorax length (THL), maximum head width $(H W)$, minimum face width (i.e., minimum distance between the eyes) $(F W)$, eye length $(E L)$, wing length $(W L)$, and wing width $(W W)$. These measurements were obtained using photographs of the insect body parts (Fig. 1), which were taken using the following procedure. All flies were dissected on $9 \mathrm{~cm}$ Petri dishes, each filled with a $0.5 \mathrm{~cm}$ thick paraffin layer. The head and thorax was then placed in a Petri dish filled with Bacto ${ }^{\circledR}$ Agar (Difco Laboratories, USA) 1\% in distilled water. Head traits were recorded from the front and thorax length from the dorsal view. Special care was taken to orient the pieces in such a way as to minimise parallax error in the photographs. The wings were mounted between slides and cover slips and then sealed with transparent nail polish (by Mauricio J. Sztem \& Cia. S.R.L). Only the left wing was measured and included in the analysis. $W W$ was defined as the distance between the point where the sectoral branch of the radial vein intersects the wing border and the point where the first branch of the anterior cubital vein joins the external border ( $D 13$ segment in Selivon et al., 2005). WL was defined as the distance between the point $R_{4+5}$ sectoral branch of radial vein intersecting the external border and the point where the medial vein joins $C u A_{1}$ (distance between points 4 and 8 in Selivon et al., 2005) (Fig. 1). The whole procedure was conducted on ice to avoid possible sample degradation, since body parts were subsequently used for molecular techniques.

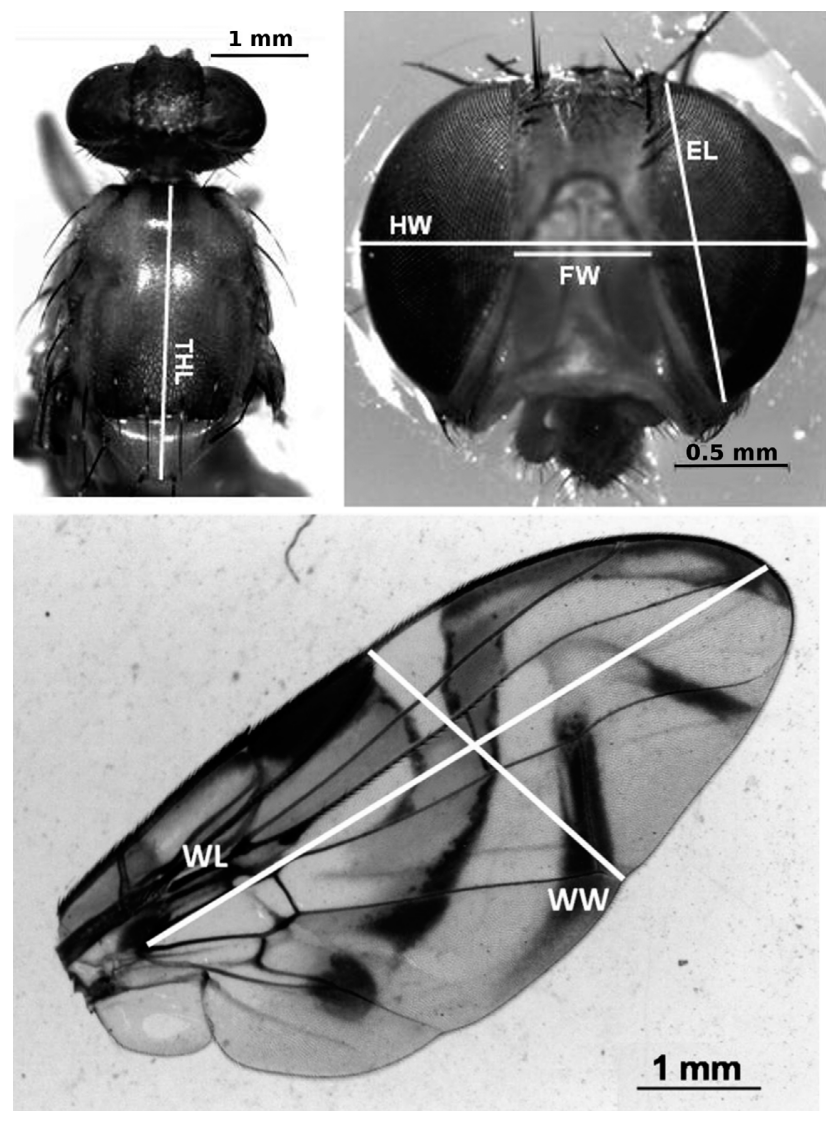

Fig. 1. Morphometric traits measured in A. fraterculus from Horco Molle, Argentina. Wing length $(W L)$, wing width $(W W)$, thorax length $(T H L)$, eye length $(E L)$, face width $(F W)$, head width $(H W)$.
All body parts were photographed using a Leica EZ4HD stereoscopic microscope with a built-in $3 \mathrm{MP}$ camera. THL, $W L$, and $W W$ were measured at $16 \times ; H W, E L$, and $F W$ at $35 \times$. Measurements were obtained with a specifically created macro for the $I m$ ageJ image system.

\section{Morphometric statistical analysis}

Phenotypic differences among flies which had emerged from different fruits were evaluated by a random generalised linear model, considering trees and fruits nested in trees as explanatory factors for phenotypic variation. For multivariate statistical analyses, all morphometric variables were standardised to mean $=0$ and variance $=1$.

The distribution of morphometric variability was evaluated by three different approaches. Method 1 was a univariate analysis applying restricted maximum likelihood (REML) using the package lme 4 (Bates et al., 2013) of $R$ software. In this case the model corresponds to the general expression:

$y_{i j k}=\mu+t_{i}+f_{i j}+e_{i j k}$

where $y_{i j k}$ represents the observation (measurement) of the trait for an individual fly from the fruit $j$ of tree $i$ and environment $k$ (which in this case would be the internal environment of the fruit), $\mu$ is the overall mean, $t_{i}$ is the effect of the tree $i, f_{i j}$ represents the effect of the fruit $j$ nested in tree $i$, and $e_{i j k}$ is the random residual error. The best model was chosen based on the lowest Akaike information criterion (AIC) or penalised log-likelihood, given by:

\section{AIC $=-2$ log-likelihood $+2(p+1)$}

where $p$ is the number of parameters in the model (Crawley, 2007).

The other two methods used a Bayesian approach to the generalised linear mixed model implemented in the package $M C$ MCglmm (Hadfield, 2010). This procedure approximates the estimates by Markov chain Monte Carlo simulations (MCMCGLMM) for univariate (method 2) and multivariate (method $3)$ analysis. For the univariate (method 2$)$ the parameters were: burn-in $=30,000$, number of iterations $=200,000$, thinning interval $=200$. For method 3 the conditions were: burn-in $=3,000$, number of iterations $=13,000$, thinning interval $=10$. The best model was based on the deviance information criterion $(D I C)$. The deviance $D$ is defined as

$D=-2 \log (\operatorname{Pr}(y \mid \Omega))$

where $\Omega$ is some parameter set of the model. The deviance is calculated at each iteration and stores each thin $^{\text {th }}$ iteration after burn-in. The mean deviance $\left(D_{m}\right)$ is calculated over all iterations. The deviance is calculated at the mean estimate of the parameters $\left[D\left(\Omega_{m}\right)\right]$ and the $D I C$ calculated as

$D I C=2 D m-D\left(\Omega_{m}\right)$

(Hadfield, 2019).

The population structure based on components of phenotypic variance was quantified by $P_{S T}$ (Brommer, 2011; Pujol et al., 2008), estimated according to the expression:

$P_{S T}=\frac{\sigma_{B}^{2}}{\sigma_{B}^{2}+2 \sigma_{W}^{2}}$

This metric is a raw approximation to Spitze's (1993) quantitative index of population divergence $\left(Q_{S T}\right)$, which relies on phenotypic rather than additive genetic data, where $\sigma_{B}^{2}$ is the variance between groups (fruits) and $\sigma_{W}^{2}$ is the variance within groups. Variances were taken from the univariate analysis (method 1) de- 
scribed above. Confidence intervals (95\%) of $P_{S T}$ estimates were obtained by bootstrap (1,000 resamplings) using the package boot (Canty \& Ripley, 2017) of $R$.

The cryptic structure based on morphometric traits was evaluated by DAPC. Similar to SSR markers, this analysis was conducted with the package adegenet of $R$, without prior information of individual groups. The most probable number of clusters $(K)$ was evaluated using the function find.clusters, covering $K$ from 1 to 14 . The best $K$ value corresponds to the lowest BIC.

Pairwise Euclidean distances between individuals were estimated using all analysed traits. Then average distances between individuals which had emerged from the same fruit and individuals which had emerged from different fruits were compared by $t$-test.

\section{RESULTS}

\section{Genetic diversity estimation}

The eight analysed loci showed high polymorphism in the studied population, with 8 to 20 alleles each $(A)$ and an allelic richness per fruit $\left(R_{A}\right)$ ranging between 1.9 and 4.1 (Table 1). Due to the high genetic variability, all individuals exhibited different multilocus genotypes (MLG) (the genotype accumulation curve is shown in Fig. S1).

The measures of multilocus gametic disequilibrium for the whole sample were non-significant $\left(I_{a}=0.204, P\right.$-value $=0.32 ; \overline{r_{D}}=0.029, P$-value $\left.=0.31\right)$ suggesting that the analysed loci are independent. When the analysis was performed for each fruit (Table S1), the trend was similar: $\overline{r_{D}}$ was significant only in two fruits $\left(\overline{r_{D}}=0.28\right.$ and $0.21, P$ values $=0.003$ and 0.009 , respectively), but after applying the Benjamini \& Hochberg (1995) correction for multiple tests they became non-significant $(P$-values $=0.057$ and 0.086 , respectively).

\section{Population structure}

A total of $137 U$ scores were obtained for all fruit $\times$ loci combinations (Table S2). Seven of them were positive and statistically significant ( $P$-values from 0.009 to 0.048 ), indicating homozygote excess. However, after applying the Benjamini \& Hochberg (1995) correction for multiple tests, all results became non-significant.

Table 1. Diversity estimates and population structure statistics in $A$. fraterculus from Horco Molle, Argentina. The number of alleles in the population $(A)$, average allelic richness per fruit $\left(R_{A}\right)$, observed heterozygosity $\left(H_{O}\right)$ expected heterozygosity within fruits $\left(H_{E}\right)$ and for the whole populations $\left(H_{T}\right)$, Wright's fixation indices $\left(F_{I S}\right)$ and genetic diversity $\left(F_{S T}\right)$ of each locus are shown. Up and Lo are the respective upper and lower limits of the $95 \%$ confidence intervals.

\begin{tabular}{lrcccccc}
\hline Locus & $A$ & $R_{A}$ & $H_{T}$ & $H_{O}$ & $H_{E}$ & $F_{S T}$ & \multicolumn{1}{c}{$F_{I S}$} \\
\hline D105 & 8 & 1.946 & 0.606 & 0.273 & 0.419 & 0.309 & 0.348 \\
A115 & 10 & 2.452 & 0.715 & 0.472 & 0.665 & 0.071 & 0.289 \\
A7 & 17 & 3.480 & 0.807 & 0.647 & 0.777 & 0.037 & 0.167 \\
A120 & 12 & 3.380 & 0.871 & 0.727 & 0.794 & 0.088 & 0.085 \\
C103 & 10 & 3.591 & 0.838 & 0.777 & 0.798 & 0.048 & 0.026 \\
A10 & 9 & 2.659 & 0.644 & 0.657 & 0.597 & 0.074 & -0.102 \\
A112 & 20 & 4.131 & 0.907 & 0.891 & 0.855 & 0.058 & -0.042 \\
A122 & 14 & 3.470 & 0.845 & 0.706 & 0.797 & 0.057 & 0.115 \\
Average & 12.5 & 3.139 & 0.779 & 0.644 & 0.712 & 0.086 & 0.096 \\
Up & & 4.014 & 0.849 & 0.761 & 0.799 & 0.147 & 0.175 \\
Lo & & 2.166 & 0.720 & 0.528 & 0.620 & 0.054 & 0.015 \\
\hline
\end{tabular}

Table 2. Wright's fixation $\left(F_{\mid S S}\right)$ index estimates and their corresponding $95 \%$ confidence intervals in $A$. fraterculus that had emerged from different guava fruits collected in Horco Molle, Argentina. Up and $L o$ are the respective upper and lower limits of the $95 \%$ confidence intervals.

\begin{tabular}{crrc}
\hline Fruit & \multicolumn{1}{c}{$F_{I S i}$} & Lo & Up \\
\hline 1001 & -0.123 & -0.278 & 0.020 \\
1002 & 0.366 & -0.190 & 0.705 \\
201 & -0.168 & -0.334 & 0.047 \\
205 & 0.070 & -0.275 & 0.333 \\
306 & 0.022 & -0.116 & 0.175 \\
312 & 0.227 & -0.018 & 0.425 \\
403 & 0.016 & -0.298 & 0.320 \\
404 & 0.087 & -0.116 & 0.283 \\
503 & 0.174 & -0.019 & 0.381 \\
507 & 0.107 & -0.017 & 0.261 \\
602 & 0.057 & -0.098 & 0.302 \\
609 & 0.157 & -0.010 & 0.314 \\
703 & 0.176 & 0.031 & 0.317 \\
711 & 0.131 & -0.192 & 0.467 \\
801 & -0.065 & -0.429 & 0.209 \\
803 & 0.209 & 0.083 & 0.340 \\
902 & 0.085 & -0.111 & 0.280 \\
904 & 0.138 & -0.007 & 0.286 \\
\hline
\end{tabular}

The summary of variability statistics (Table 1) shows heterozygote deficiency $\left(F_{I S}>0\right)$ in 6 loci and in the averaged estimates. The ratio of fruits with $F_{I S}>0$ (Table 2) was $5: 1$ which differs highly significantly from the expected $(1: 1)$ by a random distribution $\left(\chi^{2}=8.0, P\right.$-value $=0.005)$. As a consequence, the average $F_{I S}$ was positive and its whole confidence interval is above zero, showing a trend to heterozygote deficiency within fruits.

The genetic differentiation among fruits evaluated by Wright's $F_{S T}$ statistics was highly significant according to a G-statistic Monte Carlo test $\left(F_{S T}=0.087, C I=0.054-0.147\right.$, $P$-value $=5 \times 10^{-4}$, based on 1,999 permutations). Most of the genetic variance was observed at the individual level $(83 \%)$, whereas the variance among individuals $(17 \%)$ was almost evenly distributed among $(8.6 \%)$ and within fruits (among individuals) (8.4\%). When the same analysis was conducted to estimate the differentiation among flies which originated from different trees, the $F_{S T}$, although highly significant, was much lower $\left(F_{S T}=0.032, C I=0.022-0.048\right.$, $P$-value $\left.=5 \times 10^{-4}\right)$, and the percentage of variance among trees was only $3.2 \%$.

\section{Cluster analysis}

The homozygote excess within fruits observed in the population structure analysis might be attributable to cryptic structure in this $A$. fraterculus population. To evaluate possible relationships between flies which had emerged from the same fruit we obtained a minimum spanning network between genotypes (individuals) based on Reynolds' distance (Fig. 2). The plot shows that individuals (or multilocus genotypes) are not grouped according to the fruit (or tree) that they emerged from. This result suggests that each fruit is colonised by more than one female. However, the comparison of average Reynolds' distance among individuals which had emerged from the same fruit and individuals which had emerged from different fruits revealed highly 


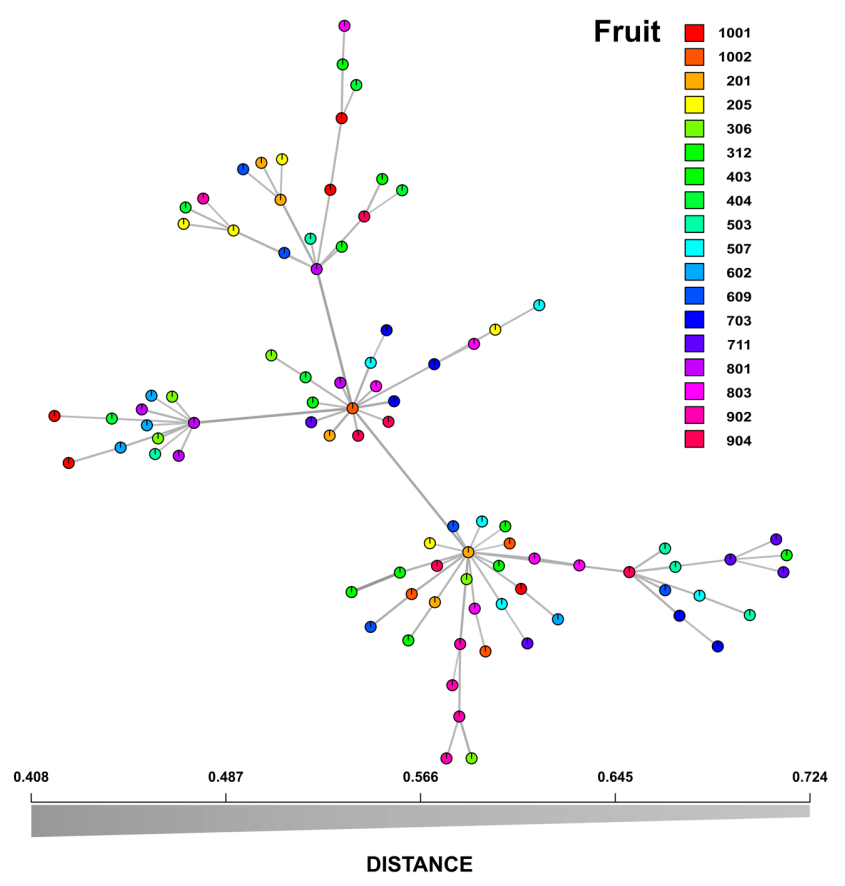

Fig. 2. Minimum spanning network for individuals of $A$. fraterculus. Dots represent multilocus genotype (individuals) and the colour indicates the fruit to which they belong.

significant differences $\left(t=4.72, P\right.$-value $\left.<10^{-5}\right)$ which are compatible with the expectation that at least some of the individuals within each fruit are full-sibs. The comparison of average kinship between individuals which had emerged from the same fruit $\left(f_{i j}=0.07\right)$ and individuals which had emerged from different fruits $\left(f_{i j} \approx 0\right)$ was also highly significant $\left(t=-8.86, P\right.$-value $\left.<10^{-15}\right)$. This result is due to the occurrence of at least some full-sibs within the same fruit and mostly non-related individuals from different fruits.

For the DAPC, the lowest Bayesian information criterion $(B I C)$ within the interval $K=1-9$ corresponded to $K$ $=3$; however, the difference in $B I C$ between $K=2$ and $K=3$ was very small (Fig. $3 \mathrm{~A}$ ) and the comparison between prior (identified by find.clusters) and posterior (after DAPC procedure) assignations showed $100 \%$ consistency in both cases. The asymmetry in individual assignment was higher for $K=2(A s=22.23)$ than for $K=3(A s=$ 19.68). Considering the higher asymmetry and that $K=2$ is a more conservative criterion, DAPC was based on this number of clusters. For the principal component analysis (PCA), 28 axes were retained that represented $87.2 \%$ of the total variance. For the discriminant analysis, only one axis
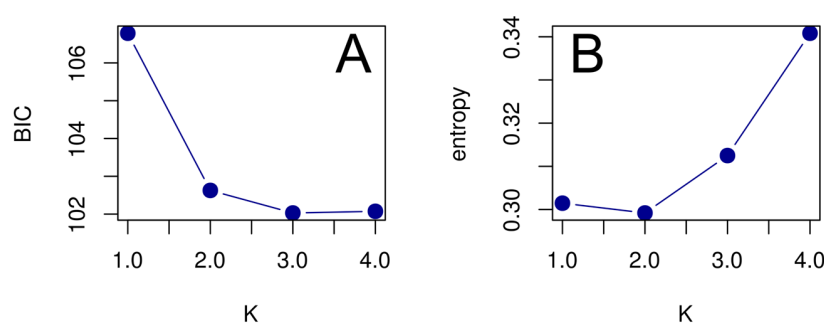

Fig. 3. A - Bayesian information criterion $(B / C)$ in function of the number of clusters $(K)$ obtained with the adegenet package. B entropy in function of $K$ obtained with the LEA package.

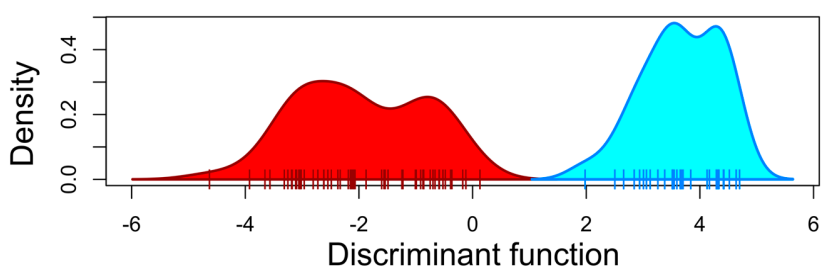

Fig. 4. Clusters obtained by discriminant analysis of principal components from molecular data in A. fraterculus from Horco Molle, Argentina.

was retained whose eigenvalue was 641.8 . The scores of individuals along this axis showed a bimodal pattern (Fig. 4). The curve in red represents the density distribution of scores of individuals of cluster 1 , whereas the light blue curve corresponds to individuals of cluster 2 . In the plot it is clear that the density curves do not overlap. This result indicates that two cryptic groups (clusters) occur in this population, which can be differentiated by their multilocus genotypes. The number of individuals assigned to clusters 1 and 2 were 58 and 31, respectively. Admixture between clusters was virtually absent (Fig. 5) and individuals within the same fruit may belong to a single or to two different clusters with similar probability.

The exploratory SNMF run identified $a=200$ and $K=2$ as the conditions satisfying the minimal entropy criterion (0.299) (Fig. 3B). The final run with these parameters assigned 53 individuals to cluster 1 (represented in red) and 36 to cluster 2 (light blue) (Fig. 5). In agreement with the results of the DAPC, SNMF also showed virtually no admixture, although in this case only five fruits had individuals belonging to a single cluster (Fig. 5). The assignment of individuals to different clusters obtained by DAPC and SNMF, despite using different algorithms, showed a consistency of $81 \%\left(\chi^{2}=29.4, P\right.$-value $\left.<10^{-7}\right)$, supporting the occurrence of two clusters that can be differentiated by their multilocus genotype.

In summary, DAPC and SNMF were consistent in showing cryptic structure with two genetic clusters. The dif-

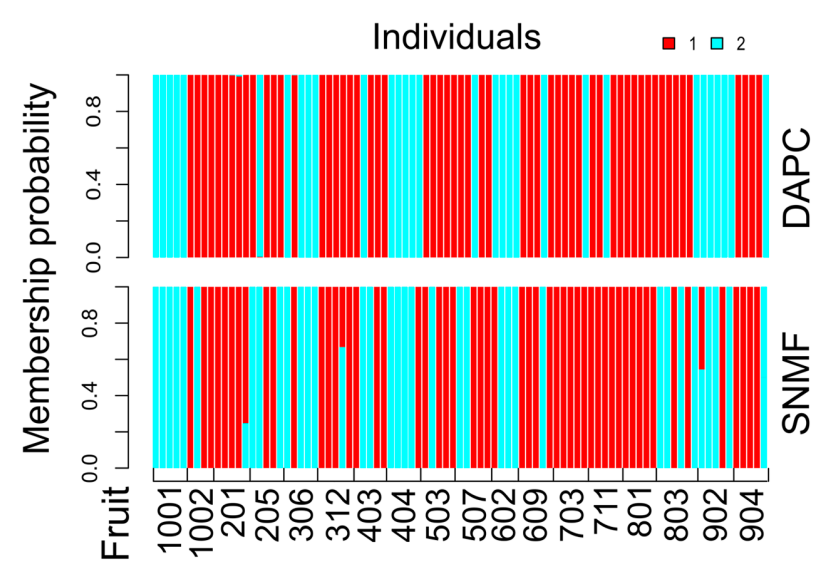

Fig. 5. Assignment of each individual to the clusters identified by discriminant analysis of principal components (DAPC) and sparse non-negative matrix factorization (SNMF) based on molecular data in $A$. fraterculus from Horco Molle, Argentina. Each bar corresponds to an individual; numbers on the bottom indicate the fruit to which they belong. 
Table 3. Means and standard errors (in $\mathrm{mm}$ ) for six morphometric traits in $A$. fraterculus which had emerged from guava fruits collected from nine trees at Horco Molle, Argentina. Acronyms for traits are defined in Fig. 1.

\begin{tabular}{|c|c|c|c|c|c|c|c|}
\hline Tree & STAT & $W L$ & $W W$ & $T H L$ & $E L$ & $F W$ & $H W$ \\
\hline \multirow{2}{*}{2} & Mean & 5.77 & 2.75 & 2.96 & 1.41 & 0.63 & 1.93 \\
\hline & SD & 0.47 & 0.16 & 0.13 & 0.07 & 0.06 & 0.09 \\
\hline \multirow{2}{*}{3} & Mean & 5.67 & 2.68 & 2.95 & 1.42 & 0.61 & 1.92 \\
\hline & SD & 0.40 & 0.13 & 0.15 & 0.06 & 0.05 & 0.07 \\
\hline \multirow{2}{*}{4} & Mean & 5.78 & 2.65 & 2.92 & 1.40 & 0.60 & 1.90 \\
\hline & SD & 0.18 & 0.12 & 0.12 & 0.04 & 0.03 & 0.05 \\
\hline \multirow{2}{*}{5} & Mean & 5.85 & 2.70 & 3.00 & 1.45 & 0.59 & 1.94 \\
\hline & SD & 0.32 & 0.14 & 0.16 & 0.07 & 0.06 & 0.11 \\
\hline \multirow{2}{*}{6} & Mean & 5.74 & 2.65 & 2.93 & 1.38 & 0.58 & 1.89 \\
\hline & SD & 0.39 & 0.18 & 0.21 & 0.11 & 0.05 & 0.13 \\
\hline \multirow{2}{*}{7} & Mean & 5.34 & 2.49 & 2.80 & 1.37 & 0.59 & 1.87 \\
\hline & SD & 0.50 & 0.26 & 0.27 & 0.10 & 0.04 & 0.08 \\
\hline \multirow{2}{*}{8} & Mean & 5.67 & 2.69 & 2.95 & 1.40 & 0.59 & 1.89 \\
\hline & SD & 0.47 & 0.13 & 0.15 & 0.07 & 0.05 & 0.10 \\
\hline \multirow{2}{*}{9} & Mean & 5.84 & 2.70 & 2.96 & 1.39 & 0.59 & 1.89 \\
\hline & SD & 0.37 & 0.17 & 0.18 & 0.07 & 0.04 & 0.09 \\
\hline \multirow{3}{*}{10} & Mean & 5.52 & 2.64 & 2.89 & 1.37 & 0.61 & 1.87 \\
\hline & SD & 0.46 & 0.13 & 0.12 & 0.05 & 0.08 & 0.07 \\
\hline & Average & 5.69 & 2.66 & 2.93 & 1.40 & 0.60 & 1.90 \\
\hline
\end{tabular}

ferentiation between the clusters identified by DAPC was evaluated by the $F_{S T}$ using assigned clusters as the grouping factor. According to this analysis, the genetic differences between these clusters were highly significant $\left(F_{S T}=\right.$ $0.10, P$-value $\left.=5 \times 10^{-4}\right)$.

\section{Morphometric statistical analysis}

Means and standard deviations of the measured traits are summarised per tree in Table 3. For all traits, the contribution of variance among trees to total variance was non-significant according to the AIC (REML) or DIC (MCMCGLMM). The remaining variance components, corresponding to among individuals from the same fruit and among fruits, differed slightly according to the estimation method (Table 4), but were about $54-66 \%$ and $34-46 \%$, respectively. This result indicates that morphometric diversity among individuals which had emerged from the same fruit is higher than the differentiation among flies which had emerged from different fruits. However, the comparison of phenotypic distances showed that individuals which had emerged from the same fruit were significantly more similar to each other than individuals which had emerged from different fruits $\left(t=6.88, P\right.$-value $\left.<10^{-10}\right)$.

For DAPC of morphometric traits, the function find.clusters failed to show a local minimum within the interval $K=$ 1-14 (Fig. 6 Box). Considering that the decrease of the $B I C$ for $K>10$ is rather low, the DAPC was conducted with this number of clusters. The PCA retained four axes, representing $94.8 \%$ of the total variance, and the discriminant analysis retained only two axes with eigenvalues of 254.4 and 33.73. The scatterplot (Fig. 6) showed that the 10 clusters were well differentiated with virtually no overlap. Individuals which had emerged from the same fruit belonged to several clusters (Fig. 7), a result consistent with the high morphometric diversity among individuals revealed by the analysis of variance components.

\section{Comparison between molecular and morphological variance distribution}

Both molecular and morphometric analysis of variance components were consistent in showing a very low contribution of the among tree variance to total variance. The ratio of among fruits / among individuals (within fruit) variances for molecular markers was close to $1: 1$. This value is similar to the result attained for phenotypic traits applying the multivariate (method 3 ) approach, where the ratio was $23: 27$. However, in univariate approaches (methods 1 and 2), among fruit variance was about half the within fruit variance, making the ratio close to $1: 2$.

The comparison between $P_{S T}$ and $F_{S T}$ estimates (Table 5) showed that confidence intervals of head traits $(H W, F W$, and $E L)$ and body size (THL) overlap with that of $F_{S T}$, suggesting that for these traits the differentiation among fruits does not differ significantly from that expected by chance. In the case of wing traits $(W W$ and $W L)$, the $P_{S T}$ was significantly higher than $F_{S T}$. This result is usually considered evidence of positive selection (Brommer, 2011), which in this case would favour different morphological optima in different fruits.

Table 4. Components of phenotypic variance of six morphometric traits in $A$. fraterculus which had emerged from guava fruits collected from nine trees at Horco Molle, Argentina, estimated by different approaches.

\begin{tabular}{|c|c|c|c|c|c|c|}
\hline \multirow{2}{*}{ Trait } & \multicolumn{2}{|c|}{ REML } & \multicolumn{2}{|c|}{ MCMC uni } & \multicolumn{2}{|c|}{ MCMC mult } \\
\hline & Fruit & Individual & Fruit & Individual & Fruit & Individual \\
\hline WL & $\begin{array}{c}0.57 \\
(0.3-1.05)\end{array}$ & $\begin{array}{c}0.42 \\
(0.33-0.56)\end{array}$ & $\begin{array}{c}10066.68 \\
(4255.32-17098.68)\end{array}$ & $\begin{array}{c}6887.29 \\
(5021.59-8535.65)\end{array}$ & $\begin{array}{c}0.77 \\
(0.38-1.27)\end{array}$ & $\begin{array}{c}0.49 \\
(0.37-0.62)\end{array}$ \\
\hline WW & $\begin{array}{c}0.37 \\
(0.18-0.72)\end{array}$ & $\begin{array}{c}0.57 \\
(0.44-0.75)\end{array}$ & $\begin{array}{c}1065.47 \\
(401.09-1866.16)\end{array}$ & $\begin{array}{c}1566.65 \\
(1186.17-2008.46)\end{array}$ & $\begin{array}{c}0.59 \\
(0.26-0.97)\end{array}$ & $\begin{array}{c}0.64 \\
(0.47-0.8)\end{array}$ \\
\hline THL & $\begin{array}{c}0.33 \\
(0.15-0.65)\end{array}$ & $\begin{array}{c}0.63 \\
(0.49-0.82)\end{array}$ & $\begin{array}{c}991.73 \\
(398.23-1753.92)\end{array}$ & $\begin{array}{c}1821.87 \\
(1398.71-2301.46)\end{array}$ & $\begin{array}{c}0.57 \\
(0.27-0.94)\end{array}$ & $\begin{array}{c}0.69 \\
(0.52-0.86)\end{array}$ \\
\hline $\mathrm{EL}$ & $\begin{array}{c}0.25 \\
(0.09-0.54)\end{array}$ & $\begin{array}{c}0.74 \\
(0.57-0.97)\end{array}$ & $\begin{array}{c}669.20 \\
(106.36-1291.16)\end{array}$ & $\begin{array}{c}1982.43 \\
(1457.19-2522.23)\end{array}$ & $\begin{array}{c}0.57 \\
(0.26-0.97)\end{array}$ & $\begin{array}{c}0.82 \\
(0.61-1.05)\end{array}$ \\
\hline FW & $\begin{array}{c}0.16 \\
(0.02-0.41)\end{array}$ & $\begin{array}{c}0.84 \\
(0.65-1.11)\end{array}$ & $\begin{array}{c}59.91 \\
(0.00-312.33)\end{array}$ & $\begin{array}{c}1228.34 \\
(877.71-1598.58)\end{array}$ & $\begin{array}{c}0.51 \\
(0.23-0.86)\end{array}$ & $\begin{array}{c}0.88 \\
(0.67-1.13)\end{array}$ \\
\hline HW & $\begin{array}{c}0.39 \\
(0.17-0.77) \\
\end{array}$ & $\begin{array}{c}0.62 \\
(0.47-0.84) \\
\end{array}$ & $\begin{array}{c}1535.51 \\
(537.63-2979.63)\end{array}$ & $\begin{array}{c}2400.28 \\
(1737.26-3163.22)\end{array}$ & $\begin{array}{c}0.64 \\
(0.31-1.08) \\
\end{array}$ & $\begin{array}{c}0.80 \\
(0.59-1.04)\end{array}$ \\
\hline
\end{tabular}

Univariate analysis applying restricted maximum likelihood (REML), univariate analysis by means of a Bayesian approach which approximates the estimates by Markov chain Monte Carlo simulations (MCMC uni), multivariate version of MCMC uni (MCMC mult). Confidence intervals (95\%) are indicated in parentheses. Acronyms for traits are defined in Fig. 1. 


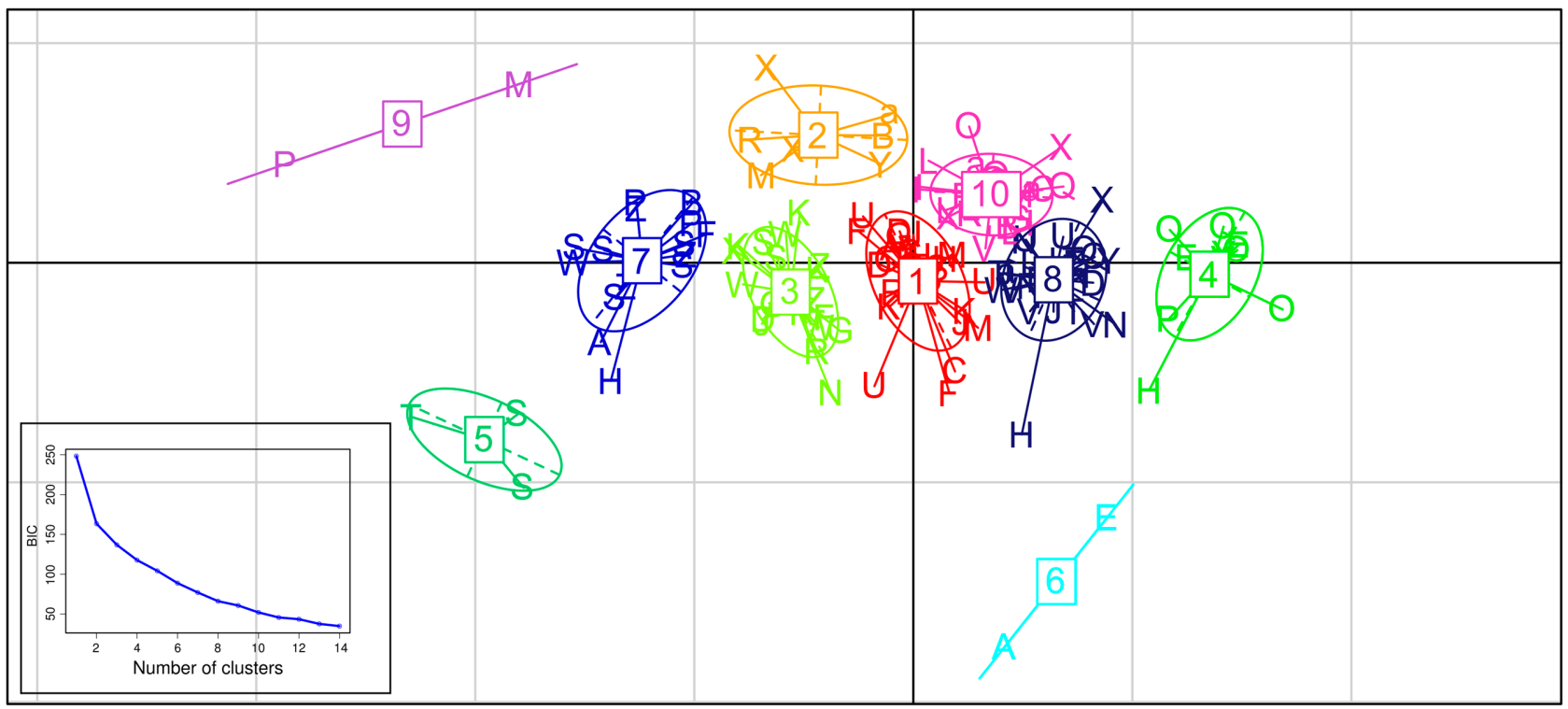

Fig. 6. Clusters obtained by discriminant analysis of principal components (DAPC) analysis for morphometric data in A. fraterculus from Horco Molle, Argentina. Ten clusters (1 to 10) are represented in different colours, and individuals by letters identifying the fruit from which they were collected. In the left bottom corner Bayesian information criterion $(B I C)$ values are plotted as a function of the number of clusters tested.

Cluster analyses conducted from molecular and morphometric datasets were not consistent. A comparison between Figs 5 and 7 shows a lack of correspondence between the clusters based on morphometric traits and either of those produced from molecular data.

Table 5. $P_{S T}$ estimated for 6 quantitative traits and $F_{S T}$ estimated from 8 SSR loci in $A$. fraterculus which had emerged from different guava fruits collected in Horco Molle, Argentina. Up and Lo are the respective upper and lower limits of the $95 \%$ confidence intervals. For highlighted values the $\mathrm{Cl}$ do not overlap that of $F_{S T}$. Acronyms for traits are defined in Fig. 1.

\begin{tabular}{cccc}
\hline Trait & $P_{S T}$ & Lo & Up \\
\hline WL & 0.404 & 0.332 & 0.429 \\
WW & 0.247 & 0.180 & 0.261 \\
THL & 0.209 & 0.140 & 0.223 \\
EL & 0.147 & 0.074 & 0.168 \\
FW & 0.089 & 0.042 & 0.093 \\
HW & 0.238 & 0.114 & 0.296 \\
F $_{\text {ST }}$ & 0.086 & 0.054 & 0.147
\end{tabular}

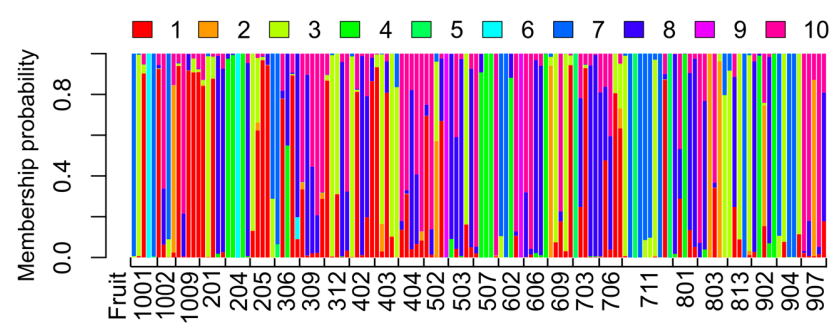

Fig. 7. Assignment of each individual to the clusters identified by discriminant analysis of principal components (DAPC) based on morphometric traits in A. fraterculus from Horco Molle, Argentina. Each bar corresponds to an individual; numbers on the bottom indicate the fruit to which they belong.

\section{DISCUSSION}

The information about population boundaries, dispersal ability, and possible internal discontinuities of natural populations is relevant to the management of pest insects. The present work applied an ecological genetics approach to evaluate the oviposition strategy of a natural population of Anastrepha fraterculus, combining morphometric data and molecular marker variation. This approach takes advantage of the discontinuous distribution of wild populations during early developmental stages (egg to third-instar larvae) which are reflected in the genetic properties of different population patches (fruits). The joint analysis of the distribution of molecular and morphological variation is relevant to the evaluation of the importance of selection and drift as processes modelling population structure.

The analysed SSR markers proved to be highly polymorphic, with high levels of allelic richness: within each fruit, each locus exhibited roughly from 2 to 4 alleles with similar frequencies. The loci were highly informative and allowed the identification of every sampled individual by its multilocus genotype. Similar to the population studied by Lanzavecchia et al. (2014), gametic disequilibrium was not observed between these loci. This fact is important because independence between loci prevents data duplication.

The differentiation among fruits, estimated through $F_{S T}$, yielded results similar to those obtained with isozyme markers by Alberti et al. (1999) in another Argentinian population of $A$. fraterculus. $F_{S T}$ estimates were close to each other and highly significant in both cases. In the study by Alberti et al. (1999), $F_{I S}$ was positive and highly significant indicating homozygote excess. Consistently, the average $F_{I S}$ estimate obtained in the present work, although lower, was also positive and significant. Homozygote excess seems to be a general trend for $A$. fraterculus popula- 
tions as it was also reported by Steck (1991). This suggests that the internal structure of $A$. fraterculus populations might be more complex than expected.

Although up to eight different morphotypes of $A$. fraterculus have been described as representing different cryptic species (Hernández-Ortiz et al., 2015), previous studies demonstrated that only one biological entity is present in Argentina and south Brazil, corresponding to the Brazilian-1 morphotype (Petit-Marty et al., 2004a, b; Alberti et al., 2008; Rull et al., 2012, 2013). However, Oroño et al. (2013), in a neighbouring area to the population analysed in this paper, observed genetic differences among flies exploiting alternative sympatric hosts (flies from peaches were significantly different than those from guava and walnuts).

A deeper fine-scale analysis of population structure is expected to contribute to identification of the boundaries of each management unit in order to establish suitable control strategies. In particular, the sterile insect technique (SIT) depends on the biological characteristics of the species, including reproductive and oviposition behaviour, and dispersal ability. Our results showed similar and significant levels of genetic variation within and among fruits. On the one hand, highly significant differences among fruits (evaluated from $F_{S T}$ estimates) are expected by drift if the number of ovipositing females per fruit is small. On the other hand, high variation within fruits, together with the occurrence of individuals of different clusters within each fruit, suggest that more than one female would be able to lay eggs in the same fruit.

Regarding oviposition behaviour, Prokopy et al. (1978, 1982, 1987) indicated that tephritid females (Ceratitis capitata and $A$. fraterculus) deposit pheromones onto the fruit surface by dragging their ovipositor, supposedly dissuading a second female of the same species to oviposit in the same fruit. On the basis of this observation, it is expected that each fruit is colonised by only one or just a few females. Different studies indicate that $A$. fraterculus females make only a few punctures per fruit (Sugayama et al., 1997), with no more than one egg per puncture (Salles, 1999). We observed in the field (data not shown) many infested fruits with more than 30 larvae, which is indicative of multiple females ovipositing on the fruit. Consistent with these observations, Dias et al. (2018) recovered an average of 53 eggs from guavas exposed for $24 \mathrm{~h}$ to ten inseminated females (i.e. approximately 5 eggs per female) in laboratory conditions.

An indirect method to estimate the number of ovipositing females per breeding site (fruits in the case of tepritid flies) is based on population structure analysis. The rationale of this approach is supported on the only assumption that for a random mating population the genetic variance among breeding sites depends solely on the population allelic frequencies and the effective size of the founder group of each site, according to the expression:

$\sigma_{q}^{2}=\frac{p q}{2 N}$ (see Falconer \& Mackay, 1996, p. 51).

As the relationship between the variance among sites and the $F_{S T}$ after any number of generations is given by

$\sigma_{q}^{2}=p q F_{S T}$

(see Falconer \& Mackay, 1996, p. 61).

The effective number of founders may be estimated as $N=1 /\left(2 F_{S T}\right)$, and the effective number of female founders would be half this value: $N_{F}=1 /\left(4 F_{S T}\right)$ (which can be used for bi- or multiallelic loci). This implies that the maximum expected $F_{S T}$ is 0.25 , corresponding to the case where each fruit is colonised by only one female.

This method was applied successfully for chromosomal polymorphisms in the cactophilic species Drosophila buzzatii, where Santos et al. (1989) obtained an estimate of approximately five ovipositing females per rotting cladode. In a natural population of $C$. capitata, Civetta et al. (1990), using the same approach on the basis of isoenzyme polymorphisms, obtained an estimate of approximately four females ovipositing per fruit. In the population analysed in this paper $F_{S T}=0.086$, yielding a rough estimate of three founder females (and three males, assuming no re-mating). This estimate might be upwards biased because we did not analyse about $1 / 3$ of the fruits (due to them each yielding fewer than four emerging flies). If they were assumed as colonised by a single female each, the average number of founder females would drop to about two. However, this number seems to be too conservative because empirical observations indicate that the number of emerged adults is much lower than the number of eggs laid, and even those fruits yielding less than four emerged adults might have been colonised by more than two females.

The average kinship $\left(f_{i j}\right)$ between flies which had emerged from the same fruit was also consistent with the estimated number of founder females. The maximum expected kinship between individuals which had emerged from the same fruit is 0.25 if they are full-sibs (only one founder female). As $f_{i j}$ is inversely proportional to the number of founder females, our result of $f_{i j}=0.07$ is close to the expectation for the occurrence of three full-sib families within each fruit.

In the population studied in this paper, no information is available about the proportion of fruits colonised by $A$. fraterculus. However, Devescovi et al. (2015) analysed the infestation patterns of an east Argentinian population of A. fraterculus and C. capitata in guava fruits collected on the ground; they found that about $36 \%$ were not infested, $46 \%$ were infested only by $A$. fraterculus, $14 \%$ by both species, and $4 \%$ by only $C$. capitata. Although these infestation ratios might be biased (due to sampling of fruits on the ground only), they reveal that a significant proportion of potential host fruits are not colonised, suggesting that the effective fly population size is lower than the carrying capacity. Even though these results cannot be completely extrapolated, we might assume that also our guava orchard is not saturated by flies. Therefore, our results indicate that the pheromones deposited by the female after oviposition might reduce, but not completely deter, oviposition 
by a second female, even when other non-attacked fruits are available in the orchard. It is probable that the consequences of pheromone marking are variable, depending on different environmental conditions and on host properties.

If the number of ovipositing females per fruit is low, flies emerging from the same fruit should be, on average, more related to each other than individuals emerging from different fruits. Such a relationship might be extended to different hierarchical levels of the population structure, generating a pattern in which the genetic similarity would decrease with increasing hierarchical levels, i.e. within fruits $>$ between fruits of the same tree $>$ between fruits of different trees, and so on. During egg to third-instar larva stages the individuals are confined to the fruit in which their eggs were laid. Selective processes inside the fruit are likely to occur mostly between full-sibs and a few different families. In the adult stage, flies disperse to search for food and breeding resources. The non-significant differentiation among trees observed in our study is compatible with a wide dispersion and high number of females colonizing each tree. Adult dispersal reduces the population fragmentation and increases the incidence of selective processes over the whole population, including viability and sexual selection components. The average fitness of each family is highly dependent on female fecundity and its ability to choose a suitable oviposition site (Sciurano et al., 2007; Segura et al., 2007; Gómez Cendra et al., 2011). Significant dispersion from the emergence site is consistent with evidence from laboratory and field cage experiments (De Lima et al., 1994; Petit-Marty et al., 2004a, b; Allinghi et al., 2007), indicating that sexual maturity requires from 16 to 21 days from adult emergence. This means that the period from emergence to highest mating activity is long enough to favour wide dispersal. This conclusion is also supported by the minimum spanning network (MSN) which showed that multilocus genotypes are not clustered according to the fruit or tree.

The DAPC and SNMF based on molecular markers suggest the occurrence of a cryptic population structure. Both methods detected two clusters with no admixture. This observation may be related to the homozygote excess tendency reported by Steck (1991) and Alberti et al. (1999) that was assumed as the consequence of complex internal population structure.

In long-term evolutionary scenarios, selection can be differentiated from demographic (migration and drift) processes because the latter are expressed genome-wide whereas selection affects only a limited number of loci (Díaz et al., 2018). Alternatively, comparison between variance components estimated for molecular and morphological traits are frequently used as a tool to evaluate selective processes in natural populations in equilibrium between drift and migration (Brommer, 2011). In our population, morphological variation among trees would be prevented by gene flow, consistent with the results from molecular data. Since the number of founders is low, differentiation among fruits mediated by drift is expected; however, the within-fruit variance component was higher for morpho- metric traits than for molecular markers. If gene flow is not restricted through generations (our case), differences in local environmental conditions (during larval development) might be a plausible explanation for the patterns of phenotypic variability (Brian et al., 2006). Since the within-fruit environment represents an unpredictable challenge during just a fraction of the generation interval (egg to third-instar larva) (Navarro-Campos et al., 2011), a plastic phenotype offers an advantage in spatially or temporally heterogeneous environments (Hollander et al., 2006). In the case of $A$. fraterculus, the environment within each fruit may be spatially variable due to several factors, including sunlight exposure, a heterogeneous distribution of microorganisms, and the presence of competitor species. A probable source of temporal environmental variation may be that eggs laid by different females are not synchronised, and therefore they face different phases of the fruit rotting process. Environmental variation among fruits might be partially hidden by the referred variation within fruits yielding a lower phenotypic variance component.

The relative within/among fruit variance ratio seems, however, to be trait dependent. The $P_{S T}-F_{S T}$ comparison showed that the among-fruit differentiation for the two wing traits was higher than expected under a neutral model. Despite the potential pitfalls of using $P_{S T}$ as an approximation of $Q_{S T}$ (Pujol et al., 2008), the differences in $P_{S T}$ estimates among different quantitative traits also support the hypothesis that wing traits might be a response to environmental challenges yielding different outcomes in different fruits. The effects of the host on wing morphology have been recorded in cactophylic species of Drosophila (Robertson, 1987; Soto et al., 2010) as well as in several tephritid species (Navarro-Campos et al., 2011; Gómez Cendra et al., 2016; Pieterse et al., 2017). There is evidence in many insects than smaller sizes are associated with lowerquality diets (Danthanarayana, 1976; Chapman, 1998). In fact, food restrictions during the larval stage represent a stress for many Drosophila species that may affect body size traits (Robertson, 1987). In C. capitata, NavarroCampos et al. (2011) observed that host fruit quality may affect wing size. The differences in $P_{S T}$ among morphometric traits found in the present work suggest that the host properties affect body shape rather than body size. This is consistent with observations by Masry \& Robertson (1978) in D. melanogaster of the effects of temperature during pupal life on the wing/thorax ratio. Wing size variation in $A$. fraterculus was shown to be related with sexual selection (Sciurano et al., 2007) and it is also expected to affect fly dispersal, another important selection component. Therefore, adult fly competitiveness in the field should be strongly determined by host quality.

The DAPC based on morphometric data yielded 10 clusters not related with the fruit that the adults emerged from. The occurrence of 2-4 clusters within each fruit is also compatible with the hypothesis of more than one founder female per fruit. Since it is unlikely that all females lay their eggs at once, it is expected that the progression in the 
rotting process is reflected in morphological differences among flies whose eggs were oviposited at different times.

In summary, molecular data analysis suggests that fruits with four or more emerged adults are founded by about 3 ovipositing females. This conclusion is also consistent with the morphometric variation observed within fruits. After emergence, flies are able to disperse widely, as evidenced by the absence of molecular and morphometric differentiation among trees. The host quality may affect fly shape, contributing to a high morphological variation of the studied population. Such variation is expected to affect fitness components, including dispersal ability and copulatory success. The knowledge generated by this fine-scale population structure analysis on a wild $A$. fraterculus population from the north of Argentina brings information on ecology and adaptive strategies used by this pest species, including its ovipositing behaviour and dispersion.

ACKNOWLEDGEMENTS. We would like to express our gratitude to T. Vera (Facultad de Agronomía y Zootecnia, Universidad Nacional de Tucumán, San Miguel de Tucumán, Argentina) for kindly providing the sample of guava fruits from Horco Molle. We would like to thank two anonymous reviewers for their helpful comments about this article. We are also indebted to L. Paulin for processing samples. The study was supported by Universidad de Buenos Aires (through grant UBACYT 2018-2021 No 20020170100270 BA to JCV) and IAEA Contract 15745 to SBL.

ETHICAL STANDARDS. The experiments performed in this study comply with the Argentinian current laws. The authors declare that they have no conflicts of interest.

\section{REFERENCES}

Abraham S., Goane L., Rull J., Cladera J., Willink E. \& Vera M.T. 2011: Multiple mating in Anastrepha fraterculus females and its relationship with fecundity and fertility. - Entomol. Exp. Appl. 141: 15-24.

Agapow P. \& Burt A. 2001: Indices of multilocus linkage disequilibrium. - Mol. Ecol. Notes 1: 101-102.

Alberti A.C., Calcagno G., Saidman B.O. \& Vilardi J.C. 1999: Analysis of the genetic structure of a natural population of Anastrepha fraterculus (Diptera: Tephritidae). - Ann. Entomol. Soc. Am. 92: 731-736.

Alberti A.C., Rodriguero M., Gómez Cendra P., Saidman B.O. \& VILARDI J.C. 2002: Evidence indicating that Argentine populations of Anastrepha fraterculus (Diptera: Tephritidae) belong to a single biological species. - Ann. Entomol. Soc. Am. 95: $505-512$.

Alberti A.C., Confalonieri V.A., Zandomeni R.O. \& Vilardi J.C. 2008: Phylogeographic studies on natural populations of the South American fruit fly Anastrepha fraterculus (Diptera: Tephritidae). - Genetica 132: 1-8.

Allinghi A., Calcagno G., Petit-Marty N., Gómez Cendra P., Segura D., Vera T., Cladera J., Gramajo C., Willink E. \& VILARDI J.C. 2007: Compatibility and competitiveness of a laboratory strain of Anastrepha fraterculus (Diptera: Tephritidae) after irradiation treatment. - Fla Entomol. 901: 27-32.

Aluja M. 1994: Bionomics and management of Anastrepha. Annu. Rev. Entomol. 39: 155-178.

Bandelt H., Forster P. \& RöHL A. 1999: Median-joining networks for inferring intraspecific phylogenies. - Mol. Biol. Evol. 16: 37-48.
Barros M.D., Novaes M. \& Malavasi A. 1983: Estudos do comportamento de oviposicáo de Anastrepha fraterculus (Wiedemann 1830) (Diptera: Tephritidae) em condicoes naturais e de laboratorio. - An. Soc. Entomol. Bras. 12: 243-247.

Baruffi L., Damiani G., Guglielmino C.R., Bandi C., Malacrida A.R. \& GASPERI G. 1995: Polymorphism within and between populations of Ceratitis capitata: comparison between RAPD and multilocus enzyme electrophoresis data. - Heredity $\mathbf{7 4 :}$ 425-437.

Bates D., Maechler M., Bolker B. \& Walker S. 2013: lme4: Linear mixed-effects models using Eigen and S4 R package. Version 104. URL: http://CRANRprojectorg/package=lme4.

Benjamini Y. \& Hochberg Y. 1995: Controlling the false discovery rate: a practical and powerful approach to multiple testing. - J. R. Statist. Soc. (B) 57: 289-300.

Brian J.V., Fernandes T., Ladle R.J. \& Todd P.A. 2006: Patterns of morphological and genetic variability in UK populations of the shore crab, Carcinus maenas Linnaeus, 1758 (Crustacea: Decapoda: Brachyura). — J. Exp. Mar. Biol. Ecol. 329: 47-54.

BRommer J.E. 2011: Whither $P_{S T}$ ? The approximation of $Q_{S T}$ by $P_{S T}$ in evolutionary and conservation biology. - J. Evol. Biol. 2: 1160-1168.

Brown A.H.D., Feldman M.W. \& Nevo E. 1980: Multilocus structure of natural populations of Hordeum spontaneum. Genetics 96: 523-536.

BuENo L.N. 2000: Las moscas de las frutas: importancia económica aspectos taxonómicos distribución mundial de los géneros de importancia económica. In: Primer Seminario Taller Sobre El Manejo de Las Moscas de Las Frutas en el Departamento de Arauca Saravena, Arauca, Saravena, Colombia, pp. 1-19.

Cáceres C., Segura D.F, Vera M.T., Wornoayporn V., Cladera J.L., Teal P.E.A., Sapountzis P., Bourtzis K., ZacharopouLOU A. \& Robinson A.S. 2009: Incipient speciation revealed in Anastrepha fraterculus (Diptera; Tephritidae) by studies on mating compatibility, sex pheromones, hybridization, and cytology. - Biol. J. Linn. Soc. 97: 152-165.

Canal N.A, Hernández-Ortiz V., Tigrero Salas J.O. \& Selivon D. 2015: Morphometric study of third-instar larvae from five morphotypes of the Anastrepha fraterculus cryptic species complex (Diptera, Tephritidae). —ZooKeys 540: 41-59.

Canty A. \& Ripley B. 2017: Boot: Bootstrap R (S-Plus) Functions. R Package Version 1.3-19. URL: https://cran.r-project. org/web/packages/boot/index.html.

Carballo V., Rodríguez L. \& Durán J. 2001: Evaluación de Beauveria bassiana para el control del picudo del chile en laboratorio. - Manejo Integrado de Plagas (Costa Rica) 62: 54-59.

CHAPMAn R.F. 1998: The Insects: Structure and Function. 4th ed. Cambridge University Press, Cambridge, UK, 929 pp.

Civetta A., Vilardi J.C., Saidman B.O., Leanza C.A. \& Cladera J.L. 1990: Estimation of the number of ovipositing females per fruit in the Mediterranean fruit fly Ceratitis capitata Wied. (Diptera: Tephritidae). - Heredity 65: 59-66.

Cladera J.L., Vilardi J.C., Juri M., Paulin L.E., Giardini M.C., Gómez Cendra P.V., Segura D.F. \& Lanzavecchia S.B. 2014: Genetics and biology of Anastrepha fraterculus: research supporting the use of the sterile insect technique (SIT) to control this pest in Argentina. - BMC Genetics 15: S12, 14 pp.

Corander J., Waldmann P. \& Sillanpaa M.J. 2003: Bayesian analysis of genetic differentiation between populations. - Genetics 163: 367-374.

Crawley M.J. 2007: The R Book. John Wiley \& Sons, Chichester, $942 \mathrm{pp}$.

Danthanarayana W. 1976: Environmentally cued size variation in the light-brown apple moth, Epiphyas postvittana (Walk.) 
(Tortricidae), and its adaptive value in dispersal. - Oecologia 26: $121-132$.

De Lima I.D., Howse P.E. \& Salles L.A.B. 1994: Reproductive behaviour of the South American fruit fly Anastrepha fraterculus (Diptera: Tephritidae): laboratory and field studies. Physiol. Entomol. 19: 271-277.

Devescovi F., Abraham S., Roriz A.K., Nolazco N., Castañeda R. , Tadeo E., Cáceres C., Segura D.F., Vera M.T., JoachimBravo I., CANAL N. \& RULL J. 2014: Ongoing speciation within the Anastrepha fraterculus cryptic species complex: the case of the Andean morphotype. - Entomol. Exp. Appl. 152: 238-247.

Devescovi F., Liendo M.C., Bachmann G.E., Bouvet J.P., Milla F.H., Vera M.T., Cladera J.L. \& Segura D.F. 2015: Fruit infestation patterns by Anastrepha fraterculus and Ceratitis capitata reveal that cross-recognition does not lead to complete avoidance of interspecific competition in nature. - Agr. Forest. Entomol. 17: 325-335.

Dias V.S., Silva J.G., Lima K.M., Petitinga C.S.C.D., Hernández-Ortiz V., Laumann R.A., Paranhos B.J., Uramoto K., Zucchi R.A. \& JoAChim-Bravo I.S. 2016: An integrative multidisciplinary approach to understanding cryptic divergence in Brazilian species of the Anastrepha fraterculus complex (Diptera: Tephritidae). - Biol. J. Linn. Soc. 117: 725-746.

Dias N.P., Nava D.E., Garcia M.S., Silva F.F. \& Valgas R.A. 2018: Oviposition of fruit flies (Diptera: Tephritidae) and its relation with the pericarp of citrus fruits. - Braz. J. Biol. 78: 443-448.

Díaz F., Lima A.L.A., Nakamura A.M., Fernandes F., Iderval S. \& DE BRITO R.A. 2018: Evidence for introgression among three species of the Anastrepha fraterculus group, a radiating species complex of fruit flies. - Front. Genet. 9: 359, 17 pp.

Dos Santos P., Uramoto K. \& Matioli S.R. 2001: Experimental hybridization among Anastrepha species (Diptera: Tephritidae): production and morphological characterization of $\mathrm{F}_{1}$ hybrids. - Ann. Entomol. Soc. Am. 94: 717-725.

El Mousadik A. \& Petit R.J. 1996: High level of genetic differentiation for allelic richness among populations of the argan tree [Argania spinosa (L.) skeels] endemic to Morocco. Theor. Appl. Genet. 92: 832-839.

Engels B. 2016: HWxtest: Exact Tests for Hardy-Weinberg Proportions. R Package Version 1.1.7. URL: https://CRAN.R-project.org/package $=$ HWxtest.

FALCONER D.S. \& MACKAY T.F.C. 1996: Introduction to Quantitative Genetics. 4th ed. Longman, Harlow, 480 pp.

Falush D., Stephens M. \& Pritchard J. 2003: Inference of population structure using multilocus genotype data: Linked loci and correlated allele frequencies. - Genetics 164: 1567-1587.

Frichot E. \& FrançOIS O. 2015: LEA: an R package for landscape and ecological association studies. - Methods Ecol. Evol. 6: 925-929.

Frichot E., Mathieu F., Trouillon T., Bouchard G. \& François O. 2014: Fast and efficient estimation of individual ancestry coefficients. - Genetics 196: 973-983.

Gómez Cendra P.V., Calcagno G., Belluscio L. \& Vilardi J.C. 2011: Male courtship behavior of the South American fruit fly Anastrepha fraterculus from an Argentinean laboratory strain. - J. Insect Sci. 11: 1-18.

Gómez Cendra P., Segura D., Alberti A. \& Vilardi J. 2014 Morphometric trait differentiation between a wild and a massreared population of Anastrepha fraterculus (Diptera: Tephritidae). - Int. J. Trop. Insect Sci. 34: S82-S89.

Gómez Cendra P.V., Paulin L.E, Oroño L., Ovruski S.M. \& VILARDI J.C. 2016: Morphometric differentiation among Anastrepha fraterculus (Diptera: Tephritidae) exploiting sympatric alternate hosts. - Environ. Entomol. 45: 508-517.
Goudet J. 2006: Hierfstat: Estimation and Tests of Hierarchical F-statistics. R Package Version 004-4. URL: https://CRAN.Rproject.org/package=hierfstat".

HADFIELD J.D. 2010: MCMC methods for multi-response generalized linear mixed models: the MCMCglmmR package. $-J$. Stat. Softw. 33: 1-22.

HADFIELD J.D. 2019: MCMCglmm Course Notes. By the author. 140 pp. URL: https://cran.r-project.org/web/packages/MCMCglmm/vignettes/CourseNotes.pdf

Hendrichs J., Vera M.T., De Meyer M. \& Clarke A.R. 2015: Resolving cryptic species complexes of major tephritid pests. —ZooKeys 5: 5-39.

Hernández-Ortiz V., Gómez-Anaya J.A., SÁnchez A., McPheron B.A. \& Aluja M. 2004: Morphometric analysis of Mexican and South American populations of the Anastrepha fraterculus complex (Diptera: Tephritidae) and recognition of a distinct Mexican morphotype. - Bull. Entomol. Res. 94: 487-499.

Hernández-Ortiz V., Bartolucci A.F., Morales-Valles P., Frías D. \& Selivon D. 2012: cryptic species of the Anastrepha fraterculus complex (Diptera: Tephritidae): a multivariate approach for the recognition of South American morphotypes. - Ann. Entomol. Soc. Am. 105: 305-318.

Hernández-Ortiz V., Canal N.A., Salas J.O.T., Ruíz-Hurtado F.M. \& DzUl-Cauich J.F. 2015: Taxonomy and phenotypic relationships of the Anastrepha fraterculus complex in the Mesoamerican and Pacific Neotropical dominions (Diptera, Tephritidae). - ZooKeys 540: 95-124.

Hollander J., Collyer M.L., Adams D.C. \& Johannesson K. 2006: Phenotypic plasticity in two marine snails: constraints superseding life history. - J. Evol. Biol. 19: 1861-1872.

IAEA 1999: The South American Fruit Fly, Anastrepha fraterculus (Wied.); Advances in Artificial Rearing, Taxonomic Status and Biological Studies. IAEA-TECDOC-1064, Vienna, 202 pp.

JOMBART T. 2008: Adegenet: an R package for the multivariate analysis of genetic markers. - Bioinformatics 24: 1403-1405.

Jombart T., Devillard S. \& Balloux F. 2010: Discriminant analysis of principal components: a new method for the analysis of genetically structured populations. - BMC Genetics 11: 94, $15 \mathrm{pp}$.

Kamvar Z.N., Brooks J.C. \& Grünwald N.J. 2015: Novel R tools for analysis of genome-wide population genetic data with emphasis on clonality. - Front. Genet. 6: 208, 10 pp.

Klassen W. \& CuRTis C.F. 2005: History of the sterile insect technique. In Dyck V.A., Hendrichs J. \& Robinson A.S. (eds): Sterile Insect Technique. Springer, Dordrecht, pp. 3-36.

Lanzavecchia S.B., Juri M., Bonomi A., Gomulski L., Scannapieco A.C., Segura D.F., Malacrida A., Cladera J.L. \& GaspERI G. 2014: Microsatellite markers from the "South American fruit fly" Anastrepha fraterculus: a valuable tool for population genetic analysis and SIT applications. - BMC Genetics 15: $\mathrm{S} 13,8 \mathrm{pp}$.

Loiselle B., Sork V., Nason J. \& Graham C. 1995: Spatial genetic structure of a tropical understory shrub, Psychotria officinalis (Rubiaceae). - Am. J. Bot. 82: 1420-1425.

Masry A.M. \& Robertson E.W. 1978: Cell size and number in the Drosophila wing. III. The influence of temperature differences during development. - Egypt. J. Genet. Cytol. 8: 71-79.

Morgante J.S., Malavasi A. \& Bush G.L. 1980: Biochemical systematic and evolutionary relationships of neotropical Anastrepha. - Ann. Entomol. Soc. Am. 73: 622-630.

Navarro-Campos C., Martínez-Ferrer M.T., Campos J.M., Fibla J.M., Alcaide J., Bargues L., Marzal C. \& Garcia-Marí F. 2011: The influence of host fruit and temperature on the body size of adult Ceratitis capitata (Diptera: Tephritidae) under 
laboratory and field conditions. — Environ. Entomol. 40: 931 938.

Nei M. \& Chesser R.K. 1983: Estimation of fixation indices and gene diversities. - Ann. Hum. Genet. 47: 253-259.

Norrbom A.L. \& Foote R.H. 1989: The taxonomy and zoogeography of the genus Anastrepha (Diptera: Tephritidae). InRobinson A.S. \& Hooper G. (eds): Fruits Flies: Their Biology Natural Enemies and Control. Elsevier, New York, pp. 15-26.

Oroño L., Paulin L., Alberti A.C., Hilal M., Ovruski S., VilarDI J.C., Rull J. \& Aluja M. 2013: Effect of host plant chemistry on genetic differentiation and reduction of gene flow among Anastrepha fraterculus (Diptera: Tephritidae) populations exploiting sympatric synchronic hosts. - Environ. Entomol. 42: 790-798.

Ovruski S., Schliserman P. \& Aluja M. 2003: Native and introduced host plants of Anastrepha fraterculus and Ceratitis capitata (Diptera: Tephritidae) in Northwestern Argentina. - J. Econ. Entomol. 96: 1108-1118.

Petit-Marty N., Vera M.T., Calcagno G., Cladera J.L., Segura D.F., Allinghi A., Rodriguero M., Gómez Cendra P., ViscarRET M.M. \& VILARDI J.C. 2004a: Sexual behavior and mating compatibility among four populations of Anastrepha fraterculus (Diptera: Tephritidae) from Argentina. - Ann. Entomol. Soc. Am. 97: 1320-1327.

Petit-Marty N., Vera M.T., Calcagno G., Cladera J.L. \& VILARDI J.C. 2004b: Lack of post-mating isolation between two populations of Anastrepha fraterculus from different ecological regions in Argentina. In Barnes B. (ed.): Proceedings of the 6th International Symposium on Fruit Flies of Economic Importance. Isteg Scientific Publications, Stellenbosch, pp. 79-82.

Pieterse W., Benítez H.A. \& Addison P. 2017: The use of geometric morphometric analysis to illustrate the shape change induced by different fruit hosts on the wing shape of Bactrocera dorsalis and Ceratitis capitata (Diptera: Tephritidae). — Zool. Anz. 269: 110-116.

Pritchard J.K., Stephens M. \& Donnelly P. 2000: Inference of population structure using multilocus genotype data. - Genetics 155: 945-959.

Prokopy R.J., Ziegler J.R. \& Wong T.T. 1978: Deterrence of repeated oviposition by fruit-marking pheromone in Ceratitis capitata. - J. Chem. Ecol. 4: 55-63.

Prokopy R.J., Malavasi A. \& Morgante J.S. 1982: Oviposition deterring pheromone in Anastrepha fraterculus flies. - $J$. Chem. Ecol. 8: 763-771.

Prokopy R.J., PApaj D.R., Opp S.B \& Wong T.T. 1987: Intra-tree foraging behaviour of Ceratitis capitata flies in relation to host fruit density and quality. - Entomol. Exp. Appl. 45: 251-258.

Pujol B., Wilson A.J., Ross R.I.C. \& Pannell J.R. 2008: Are $\mathrm{Q}(\mathrm{ST})-\mathrm{F}(\mathrm{ST})$ comparisons for natural populations meaningful? - Mol. Ecol. 17: 4782-4785.

R Core Team 2017: R: A Language and Environment for Statistical Computing. R Foundation for Statistical Computing, Vienna. URL: https://www.R-project.org/

ReYNOLDS J., WeIR B.S. \& COCKERHAM C.C. 1983: Estimation of the coancestry coefficient: basis for a short-term genetic distance. - Genetics 105: 767-779.

ROBERTSON F.W. 1987: Variation of body size within and between wild populations of Drosophila buzzatii. — Genetica 72: 111125.

Rocha L.S. \& SELIVON D. 2004: Studies on highly repetitive DNA in cryptic species of the Anastrepha fraterculus complex (Diptera: Tephritidae). In Barnes B. (ed.): Proceedings of the 6th International Symposium on Fruit Flies of Economic Importance. Isteg Scientific Publications, Stellenbosch, pp. 415-418.
RoRIZ A.K., JAPYASSÚ H.F. \& JOACHIM-Bravo I.S. 2017: Incipient speciation in the Anastrepha fraterculus cryptic species complex: reproductive compatibility between $A$. sp.1 aff. fraterculus and A. sp.3 aff. fraterculus. - Entomol. Exp. Appl. 162: 346-357.

Roser L.G., Ferreyra L.I., Saidman B.O. \& Vilardi J.C. 2017: EcoGenetics: An R package for the management and exploratory analysis of spatial data in landscape genetics. - Mol. Ecol. Resour. 17: e241-e250.

Rousset F. \& RAYMOND M. 1995: Testing heterozygote excess and deficiency. - Genetics 140: 1413-1419.

Rull J., Abraham S., Kovaleski A., Segura D.F., Islam A., WornoAyporn V., Dammalage T., Santo Tomas U. \& Vera M.T. 2012: Random mating and reproductive compatibility among Argentinean and southern Brazilian populations of Anastrepha fraterculus (Diptera: Tephritidae). - Bull. Entomol. Res. 102: 435-443.

Rull J., Abraham S., Kovaleski A., Segura D.F., Mendonza M., LIENDO M.C. \& VERA M.T. 2013: Relative importance of prezygotic and postzygotic barriers to gene flow among three cryptic species within the Anastrepha fraterculus complex. - Entomol. Exp. Appl. 148: 213-222.

SALLES L.A. 1999: Biology of Anastrepha fraterculus. In International Atomic Energy Agency (ed.): IAEA-TECDOC-1064. The South American Fruit Fly, Anastrepha fraterculus (Wied.); Advances in Artificial Rearing, Taxonomic Status and Biological Studies. Proceedings of a Workshop Organized by the Joint FAO/IAEA Division of Nuclear Techniques in Food and Agriculture and held in Vina del Mar, Chile, 1-2 November 1996. International Atomic Energy Agency, Vienna, pp. 139-145.

Santos M., Ruiz A. \& Fontdevila A. 1989: The evolutionary history of Drosophila buzzatii. XIII. Random differentiation as a partial explanation of chromosomal variation in a structured natural population. - Am. Nat. 133: 183-197.

Sciurano R., Segura D., Rodriguero M., Gómez Cendra P., Allinghi A., Cladera J.L. \& Vilardi J. 2007: Sexual selection on multivariate phenotypes in Anastrepha fraterculus (Diptera: Tephritidae) from Argentina. - Fla Entomol. 90: 163-170.

Segura D., Petit-Marty N., Sciurano R., Vera T., Calcagno G., Allinghi A., Gómez Cendra P., Cladera J. \& Vilardi J. 2007: Lekking behavior of Anastrepha fraterculus (Diptera: Tephritidae). - Fla Entomol. 9: 154-162.

Selivon D. \& Perondini A.L.P. 1998: Eggshell morphology in two cryptic species of the Anastrepha fraterculus complex (Diptera: Tephritidae) — Ann. Entomol. Soc. Am. 91: 473-478.

Selivon D., Perondini A.L.P. \& Morgante J.S. 1999: Haldane's rule and other aspects of reproductive isolation observed in the Anastrepha fraterculus complex (Diptera, Tephhritidae). Genet. Mol. Biol. 22: 507-510.

Selivon D., Vretos C., Fontes L. \& Perondini A.L.P. 2004: New variant forms in the Anastrepha fraterculus complex (Diptera: Tephritidae). In Barnes B. (ed.): Proceedings of the 6th International Symposium on Fruit Flies of Economic Importance. Isteg Scientific Publications, Stellenbosch, pp. 253-258.

Selivon D., Perondini A.L.P. \& Morgante J.S. 2005: A geneticmorphological characterization of two cryptic species of the Anastrepha fraterculus complex (Diptera: Tephritidae). Ann. Entomol. Soc. Am. 98: 367-381.

Smith-Caldas M.R., McPheron B.A., Silva J.G. \& Zucchi R.A. 2001: Phylogenetic relationships among species of the fraterculus group (Anastrepha: Diptera: Tephritidae) inferred from DNA sequences of mitochondrial cytochrome oxidase I. Neotrop. Entomol. 30: 565-573.

Soto I.M., Soto E.M., Corio C., Carreira V.P., Manfrin M. \& Hasson E. 2010: Male genital and wing morphology in the 
cactophilic sibling species Drosophila gouveai and Drosophila antonietae and their hybrids reared in different host plants. Environ. Entomol. 39: 865-873.

SpITZE K. 1993: Population structure in Daphnia obtusa: quantitative genetic and allozymic variation. - Genetics 135: 367 374.

STECK G.J. 1991: Biochemical systematics and population genetic structure of Anastrepha fraterculus and related species (Diptera: Tephritidae). - Ann. Entomol. Soc. Am. 84: 10-28.

Stone A. 1942: Fruit Flies of the Genus Anastrepha. Miscellaneous Publication 439. USDA, Washington DC, $112 \mathrm{pp}$.

Sugayama R.L., Branco E.S., Malavasi A., Kovaleski A. \& Nora I. 1997: Oviposition behavior of Anastrepha fraterculus in apple and diel pattern of activities in an apple orchard in Brazil. - Entomol. Exp. Appl. 83: 239-245.

Sutton B.D., Steck G.J., Norrbom A.L., Rodrigues E.J., Srivastava P., Nolazco Alvarado N., Colque F., Landa E.Y., Sánchez J.J., Quisberth E., Arévalo Peñaranda E., Clavijo P.A., Alvarez-Baca J.K., Guevara Zapata T. \& Ponce P. 2015: Nuclear ribosomal internal transcribed spacer I (ITS1) variation in the Anastrepha fraterculus cryptic species complex (Diptera, Tephritidae) of the Andean region. — ZooKeys 540: 175-191.

Tang J., Hanage W.P., Fraser C. \& Corander J. 2009: Identifying currents in the gene pool for bacterial populations using an integrative approach. - PLoS Comput. Biol. 5: e1000455, $18 \mathrm{pp}$.

UchôA-Fernandes M.A., Molina R.M. da S., de Oliveira I., ZuCCHI R.A., CANAL N.A. \& Díaz N.B. 2003: Larval endoparasitoids (Hymenoptera) of frugivorous flies (Diptera, Tephritoidea) reared from fruits of the cerrado of the State of Mato Grosso do Sul, Brazil. - Rev. Bras. Entomol. 47: 181-186.

VaníčKová L., Hernández-Ortiz V., Joachin-Bravo I.S., Dias V., Roriz A.K.P., Laumann R.A., Mendonc A.L., Paranhos B.A.J. \& NASCIMENTO R.R. 2015: Current knowledge of the species complex Anastrepha fraterculus (Diptera, Tephritidae) in Brazil. - ZooKeys 540: 211-237.

WeIR B.S. \& COCKERHAM C.C. 1984: Estimating $F$-statistics for the analysis of population structure. - Evolution 38: 13581370.

Vera M.T., Cáceres C., Wornoayporn V., Islam A., Robinson A.S., De La Vega M.H., Hendrichs J. \& Cayol J.P. 2006: Mating incompatibility among populations of the South American fruit fly Anastrepha fraterculus (Diptera: Tephritidae). - Ann. Entomol. Soc. Am. 99: 387-397.

WrIGHT S. 1951: The genetical structure of populations. - Ann. Eugen. 15: 323-354.

WRIGHT S. 1965: The interpretation of population structure by $F$ statistics with special regard to systems of mating. - Evolution 19: 395-420.

Yamada S.M. \& Selivon D. 2001: Rose, an eye color mutation in a species of the Anastrepha fraterculus complex (Diptera: Tephritidae). - Ann. Entomol. Soc. Am. 94: 592-595.

Received September 6, 2018; revised and accepted March 7, 2019 Published online April 18, 2019

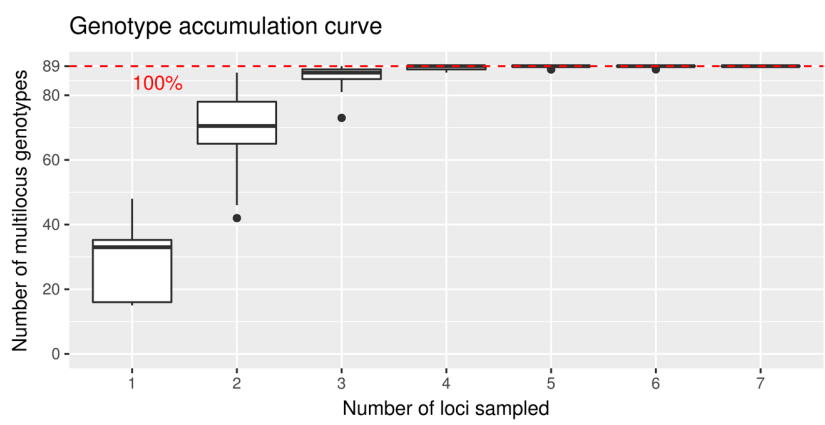

Fig. S1. Genotype accumulation curve showing the minimum number of simple sequence repeat (SSR) loci necessary to discriminate between individuals in a population of $A$. fraterculus from Horco Molle, Argentina.

Table S1. Measures of gametic disequilibrium in the population of A. fraterculus from Horco Molle, Argentina.

\begin{tabular}{rrlrl}
\hline Fruit & \multicolumn{1}{c}{$I_{a}$} & $p . l_{a}$ & \multicolumn{1}{c}{$\overline{r_{D}}$} & $p . \overline{r_{D}}$ \\
\hline 1001 & -0.555 & 0.927 & -0.083 & 0.928 \\
1002 & -0.453 & 0.746 & -0.095 & 0.691 \\
201 & -0.563 & 0.888 & -0.122 & 0.943 \\
205 & 0.671 & 0.084 & 0.139 & 0.064 \\
306 & -0.027 & 0.477 & -0.004 & 0.476 \\
312 & -0.337 & 0.775 & -0.060 & 0.764 \\
403 & 1.484 & 0.009 & 0.280 & 0.003 \\
404 & 0.097 & 0.378 & 0.015 & 0.373 \\
503 & -0.282 & 0.795 & -0.052 & 0.780 \\
507 & -0.529 & 0.967 & -0.081 & 0.958 \\
602 & 0.022 & 0.421 & 0.004 & 0.420 \\
609 & -0.240 & 0.760 & -0.038 & 0.759 \\
703 & 0.329 & 0.367 & 0.049 & 0.375 \\
711 & 1.290 & 0.012 & 0.210 & 0.009 \\
801 & 0.133 & 0.301 & 0.029 & 0.281 \\
803 & 0.379 & 0.479 & 0.057 & 0.486 \\
902 & -0.022 & 0.576 & -0.003 & 0.576 \\
904 & 0.497 & 0.247 & 0.074 & 0.260 \\
\hline
\end{tabular}

Index of association $\left(I_{\mathrm{a}}\right)$ (Brown et al., 1980), significance of $I_{a}(p$. $l_{\mathrm{a}}$ ), standardised index of association $\left(\overline{r_{D}}\right)$ (Agapow \& Burt, 2001), significance of $\overline{r_{D}}\left(p . \overline{r_{D}}\right)$.

Table S2. Significance ( $P$-values) of the $U$ score test for heterozygote excess/deficiency in eight loci studied in $A$. fraterculus which had emerged from different guava fruits collected in Horco Molle, Argentina. Significant values are in bold type.

\begin{tabular}{ccccccccc}
\hline Fruit & D105 & A115 & A7 & A120 & C103 & A10 & A112 & A122 \\
\hline 1001 & 0.762 & 0.381 & 0.794 & 0.229 & 0.571 & 0.381 & 0.356 & 0.111 \\
1002 & - & 0.333 & 0.429 & - & $\mathbf{0 . 0 2 9}$ & 0.229 & 0.571 & 0.914 \\
201 & 0.800 & - & 0.156 & 0.648 & 0.127 & 0.432 & 0.127 & 0.889 \\
205 & - & 0.229 & 0.952 & $\mathbf{0 . 0 1 6}$ & 0.356 & 0.206 & 0.648 & 0.143 \\
306 & 0.143 & 0.889 & 0.794 & 0.775 & 0.457 & 0.667 & 0.495 & 0.775 \\
312 & - & 0.333 & 0.111 & 0.257 & 0.603 & 0.127 & 0.156 & 0.067 \\
403 & 0.143 & 1.000 & 0.851 & 0.361 & 0.127 & 0.127 & 0.432 & 0.060 \\
404 & 0.619 & $\mathbf{0 . 0 4 8}$ & 0.127 & 0.603 & 0.111 & 0.381 & 0.851 & $\mathbf{0 . 0 4 1}$ \\
503 & - & 0.200 & 0.952 & 0.546 & 0.711 & 0.340 & $\mathbf{0 . 0 4 1}$ & 0.143 \\
507 & 0.333 & 0.762 & 0.952 & 0.257 & 0.546 & 0.762 & 0.857 & 0.257 \\
602 & 0.143 & 0.429 & 0.571 & 0.800 & 0.800 & 0.857 & 0.743 & 0.648 \\
609 & 1.000 & 1.000 & 0.143 & 0.289 & 0.257 & 0.889 & 0.305 & 0.111 \\
703 & 0.857 & 0.143 & 0.143 & 1.000 & 0.514 & 0.111 & 0.424 & 0.851 \\
711 & 0.111 & $\mathbf{0 . 0 1 0}$ & 0.889 & 0.127 & 0.279 & 0.111 & 0.851 & 0.127 \\
801 & - & 1.000 & 0.648 & 0.667 & 0.079 & 1.000 & 0.495 & 0.400 \\
803 & 1.000 & 0.086 & $\mathbf{0 . 0 4 4}$ & 0.857 & 0.244 & 0.172 & 0.806 & 0.698 \\
902 & 1.000 & 0.698 & 0.086 & 0.857 & 0.079 & 0.635 & 0.330 & 0.743 \\
904 & 1.000 & 0.086 & 0.619 & 0.333 & 0.743 & 0.698 & 0.149 & 0.356 \\
\hline
\end{tabular}

